\title{
EFFECT OF HEAT INPUT AND HEAT TREATMENT ON THE MECHANICAL PROPERTIES OF IS2062-IS103 Cr 1 STEEL WELDMENTS
}

\author{
M. Bala Chennaiah ${ }^{1}$, Dr. P.Nanda Kumar ${ }^{2}$, Dr. K.Prahlada Rao ${ }^{3}$ \\ Assistant Professor in ME Department, V.R.Siddhartha Engineering College, Vijayawada. \\ Professor in ME Department, N.B.K.R Institute of Engineering \& Technology, Vidyanagar. \\ Professor in ME Department, J.N.T.University College of Engineering, Ananthapuram.
}

\begin{abstract}
:
In the proposed research work the mechanical properties of IS2062-IS103 Cr 1 steel weldments was studied. Welded joints are prepared by using GMAW welding processes with filler wire is AWS A5.18 ER 70 S-6 at different heat inputs conditions with pre heat treatment. The annealing, normalizing and tempering heat treatment processes are applied to weldments. The mechanical properties such as tensile strength, impact and hardness and microstructures of the weldments are observed.The results are compared with reference to heat inputs and heat treatments.
\end{abstract}

\section{Key words:}

Heat Input,Mechanical Properties, Post Weld Heat Treatment,WZ,BM,HAZ

\section{Introduction:}

In many problems in cyclic temperature of dissimilar metals in the manufacturing industry often plays a vital role. Applications of welding dissimilar metals and alloys are widely found in automobile machinery, pressure vessels etc. The chemical compositions of the metals make their dissimilarities the metals. Particularly, weldability and other mechanical properties are much affected by the chemical composition of the dissimilar steel alloys. During the manufacturing of structural steels some elements are particularly added to improve the properties, but some inevitable elements may be present added from the scrap materials during the production of steel. Individual dissimilar metals properties vary with other alloy dissimilar metals, because of the variation of the alloying elements. Hence welding of dissimilar metals may compose different properties of the metals. In order to improve the performance of weldments with minimum cost, an appropriate welding procedure is to be identified.

Ramazan Kayacan et al [1], investigated on "The effect of Pre-Post welded heat treatment variables on the strain-age cracking welded components". This hardened nickel based super alloys are used in power plants, air space applications at hot section equipments. In this Rene 41 material is selected, during the fabrication strain age cracking is avoided based on the An optimum combination of pre-post weld heat treatment variables like heating rate, soaking time and cooling rate. The grains which are light and distributed homogenously will be changed after 
applying the Pre-PWHT processes. Many super alloys consist of various types of carbides and other phases distributed throughout the matrix and along the grain boundaries. Generally the carbide of super alloys in $\mathrm{MC}$ (Matrix constitute), $\mathrm{M}_{23} \mathrm{C}_{6} \& \mathrm{M}_{6} \mathrm{C}$ and phase changes provide the useful high temperature properties. The thermal expansion and contraction during heating and subsequently cooling as well as material plastic deformation at elevated temperatures result in inevitable distortions and residual stresses $[2,3]$ in the joint and the parent metals, which greatly effects the fabrication tolerance and quality. In current industrial practice, welding processes are developed largely based on trial and error experiments incorporating with engineers' knowledge and experience of previous similar designs. To avoid the damages of high strength low alloy steels of dissimilar joints are preferred, suitable heat input are selected [4]. After that one of the most important notice is edge preparation, it means that to avoid the welding defects such as lack of penetration, air bubbles formation, under cut and segregation of different chemical compositions due to change in microstructures of base metal, heat effected and welded zones of each metals.

Tensile test, harpy-V test and hardness samples are prepared[5-9] and evaluated from the IS2062 as compared to the earlier PWHT conditions .Even though there was considerable research during the past decades, the problems of strain age cracking remained unsolved. For this reason the use of strain cracking susceptible alloys in highly restrained components at elevated temperatures has generally been avoided, and in many cases other less crack susceptible but weaker materials have been used [10-13]. C.R.Brooks et al [14], where Post weld solution was used heat treated using optimum heat treatment variable determined in the first stage of the study and then PW ageing heat treated according to previous literature. Here PW ageing heat treatment as recommended is avoiding strain age cracking during the PW solution heat treatment.

However there is no enough work on the influence of low heat, high heat inputs and PWHT on mechanical Micro structural of dissimilar welded joints. The proposed research work is concentrated on investigating the influence of heat input and PWHT on the mechanical properties in a dissimilar (IS2062-IS103Cr 1) welded joints.

\section{Experimental Procedure:}

\subsection{Welding Procedure:}

The base metal steels of IS2062\&IS103Cr1 alloy metals of the size $250 \mathrm{~mm} \times 100 \mathrm{~mm} \times 10 \mathrm{~mm}$ thick were taken. Edge Preparation was done for welding as Single V butt joint. Edge $45^{0}$ bevelling was performed. After Edge preparation the work pieces of material were paired using filler material. We considered $10 \mathrm{~mm}$ thickness of plate, before doing Welding; preheating $\left(120^{\circ} \mathrm{C}\right)$ was performed using oxyacetylene flame. This would prevent the moisture in the metal, help in distortion control and crack minimization. Here we used the GMAW Welding with Copper Coated AWS A5.18 ER 70 S-6 Mild Steel with diameter 1.2mm as filler metal. Copper coating on Mild steel is preferred since current conducts easily and to prevent rust. The chemical properties of base metals and copper coated mild steel a shown in table: 1.Anti spatter spray is applied on the plates for easy clean up after a flux core MIG welder. $\mathrm{Co}_{2}$ is used as the inert gas. Before making welding, the work pieces were fixed on a fixer to avoid distortion in the plates. Welding is done for 5 passes with respect to average voltage, current, inert gas flow and wire feed rate. Thermocouples are clamped at multiple spots to observe the temperature distribution along the traverse length. This helped us to locate different zones (this technique is to be replaced by 
hardness technique) of weldment viz. base metal, heat affected zone and welded zone. Heat input is a relative measure of the energy transferred per unit length of weld. It is important characteristic because, like preheat and interpass temperature, it influences or effects the mechanical properties and metallurgical structure of the weld and the HAZ. The heat input equation is as follows

Heat input $=[(\mathrm{V} \times \mathrm{A} \times 60) /(\mathrm{S} \times 1000)] \times$ efficiency,$($ For MIG, efficiency $=0.9)$ $=[(30 \times 180 \times 60) /(3.3126 \times 1000)] \times 0.9=1.4712(\mathrm{kj} / \mathrm{mm})$

\begin{tabular}{|c|l|c|c|c|c|c|c|}
\hline \multirow{2}{*}{ S.No } & \multirow{2}{*}{ Name of Material } & \multicolumn{5}{|c|}{ Composition in \% of Weight } \\
\cline { 3 - 8 } & & $\mathrm{C}$ & $\mathrm{Mn}$ & $\mathrm{Si}$ & $\mathrm{Cr}$ & $\mathrm{S}$ & $\mathrm{P}$ \\
\hline 1. & Mild steelIS-2062 & 0.22 & 1.5 & 0.40 & - & 0.045 & 0.045 \\
\hline 2. & EN 31 (Or) IS 103 Cr1 & 1.5 & 0.52 & 0.22 & 1.3 & 0.05 & 0.05 \\
\hline 3. & Copper Coated Mild Steel & 0.1 & 1.86 & 0.73 & 0.2 & 0.30 & 0.03 \\
\hline
\end{tabular}

Table No: 1 Chemical composition of Base metals and filler wire.

\subsection{Tensile test samples:}

The tensile test samples are prepared as per procedure that is used to cut from the weldment in the fig (1). While conducting tensile test, firstly we measured initial length and the diameter of the test piece and noted and then test piece is mounted on the testing machine and then load is applied and after sometime test piece is elongated and necking is formed and then loading process continued until fracture. This test is conducted for test pieces of 4 joints. Heat treatment is a stage wise procedure in the fabrication of structures and is often forgotten; but it has perhaps more wide-reaching and important ramifications than many of the other stages in fabrications of structures or components.

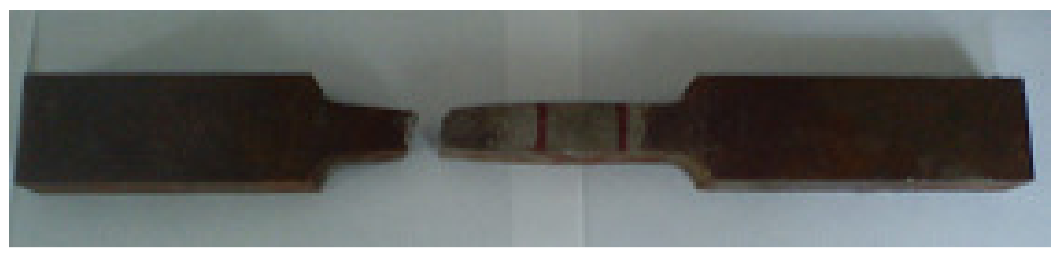

Fig no (1): Tensile Test sample.

\subsection{Impact test samples:}

This test samples are prepared and tested as per ASTM -IS2062 procedure. The samples are cut longitudinally to the weld axis with notch the middle of the welded area specimen. This work is carried out at room temperature. 


\subsection{Hardness:}

The sample preparation and evolution is carried based on ASTM procedure. The hardness measure is done at different zones of weldment namely base metal; HAZ and WZ and valves are tabulated.

\section{Results and Discussion:}

\subsection{Tensile test:}

The tensile test is conducted on before PWHT and after PWHT test specimens. One of the most significant observation at different heat treatment conditioned test sample give higher values and their comparisons based on BHT and AHT are shown in table no: 2 and fig: 2 Then the other samples.

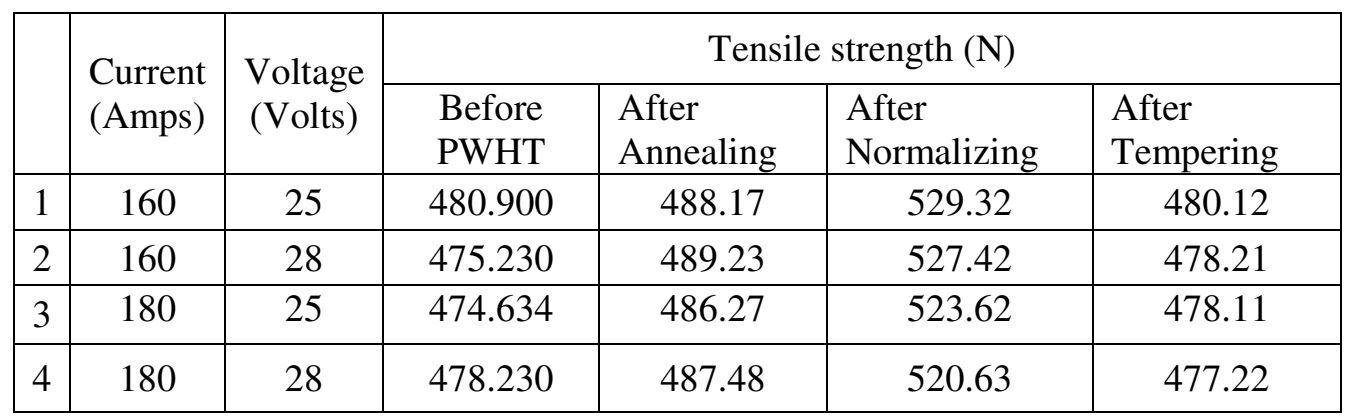

Table no (2): Tensile strength results for IS 2062 \& IS $103 \mathrm{Cr} 1$ joint for before heat treatment after heat treatment.

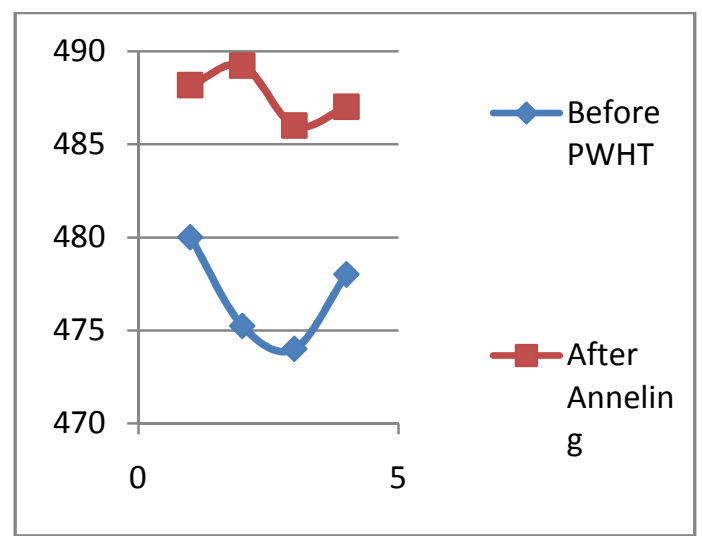


International Journal of Advances in Materials Science and Engineering (IJAMSE) Vol.4, No.3, July 2015
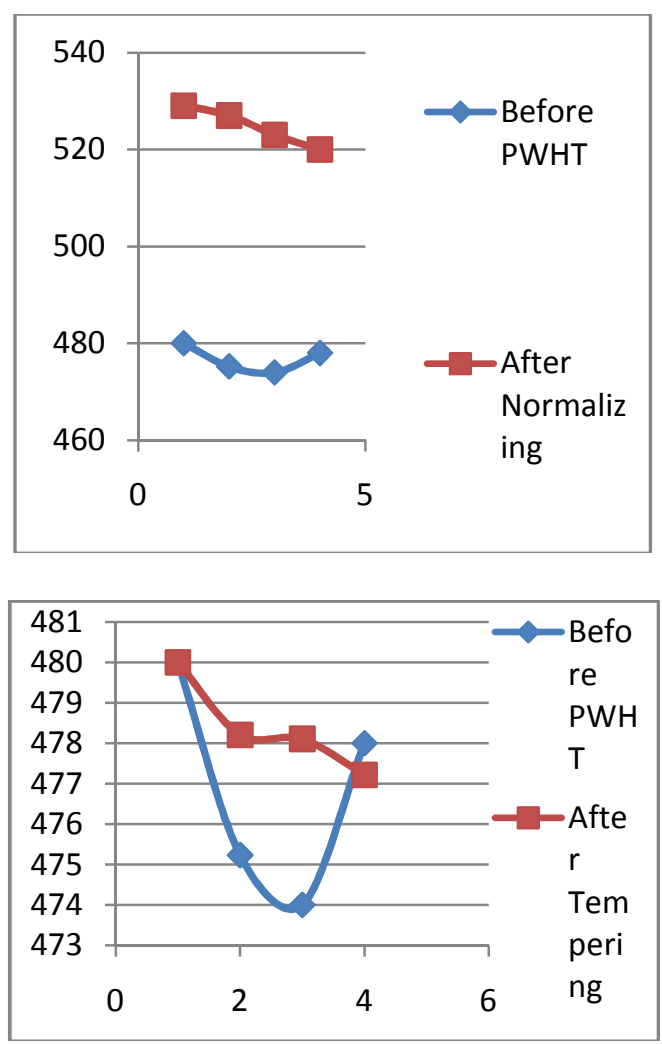

Fig no (2): Tensile strength for IS $2062 \&$ IS $103 \mathrm{Cr} 1$ joints low heat input \& high heat input for both

\subsection{Impact strength:}

B.H.T \& A.H.T of each condition

While conducting Impact test firstly we have to prepare the test piece as per dimensions by using milling machine and also by using $\mathrm{V}$ cutter in order to make a notch up to $2 \mathrm{~mm}$ thickness. The arrangement of test setup consist of big sized pendulum is used to hit the prepared samples at an standard height, at the same time some amount of energy is absorbed by the samples from the pendulum to fracture the test samples, the results obtained from the testing machine were tabulated. Here the minimum impact energy is observed in case of BHT and maximum energy is observed in case of annealing conditions of the test samples shown in table no: 3 and fig no: 3 .

\begin{tabular}{|c|c|c|c|c|c|c|}
\hline & \multirow{2}{*}{$\begin{array}{c}\text { Curre } \\
\text { nt } \\
\text { (Amp } \\
\text { s) }\end{array}$} & \multirow{2}{*}{$\begin{array}{l}\text { Volta } \\
\text { ge } \\
\text { (Volt } \\
\text { s) }\end{array}$} & \multicolumn{4}{|c|}{ Impact strength $(\mathrm{J})$} \\
\hline & & & $\begin{array}{l}\text { Before } \\
\text { PWHT }\end{array}$ & $\begin{array}{c}\text { After } \\
\text { Annealing }\end{array}$ & $\begin{array}{c}\text { After } \\
\text { Normalizing }\end{array}$ & $\begin{array}{c}\text { After } \\
\text { Tempering }\end{array}$ \\
\hline 1 & 160 & 25 & 82 & 92 & 89 & 84 \\
\hline 2 & 160 & 28 & 80 & 91 & 90 & 82 \\
\hline 3 & 180 & 25 & 72 & 78 & 75 & 74 \\
\hline 4 & 180 & 28 & 70 & 75 & 73 & 72 \\
\hline
\end{tabular}

Table no (3): Impact strength results for IS 2062 \& IS 103 Cr1 joint for before heat treatment. 
International Journal of Advances in Materials Science and Engineering (IJAMSE) Vol.4, No.3, July 2015
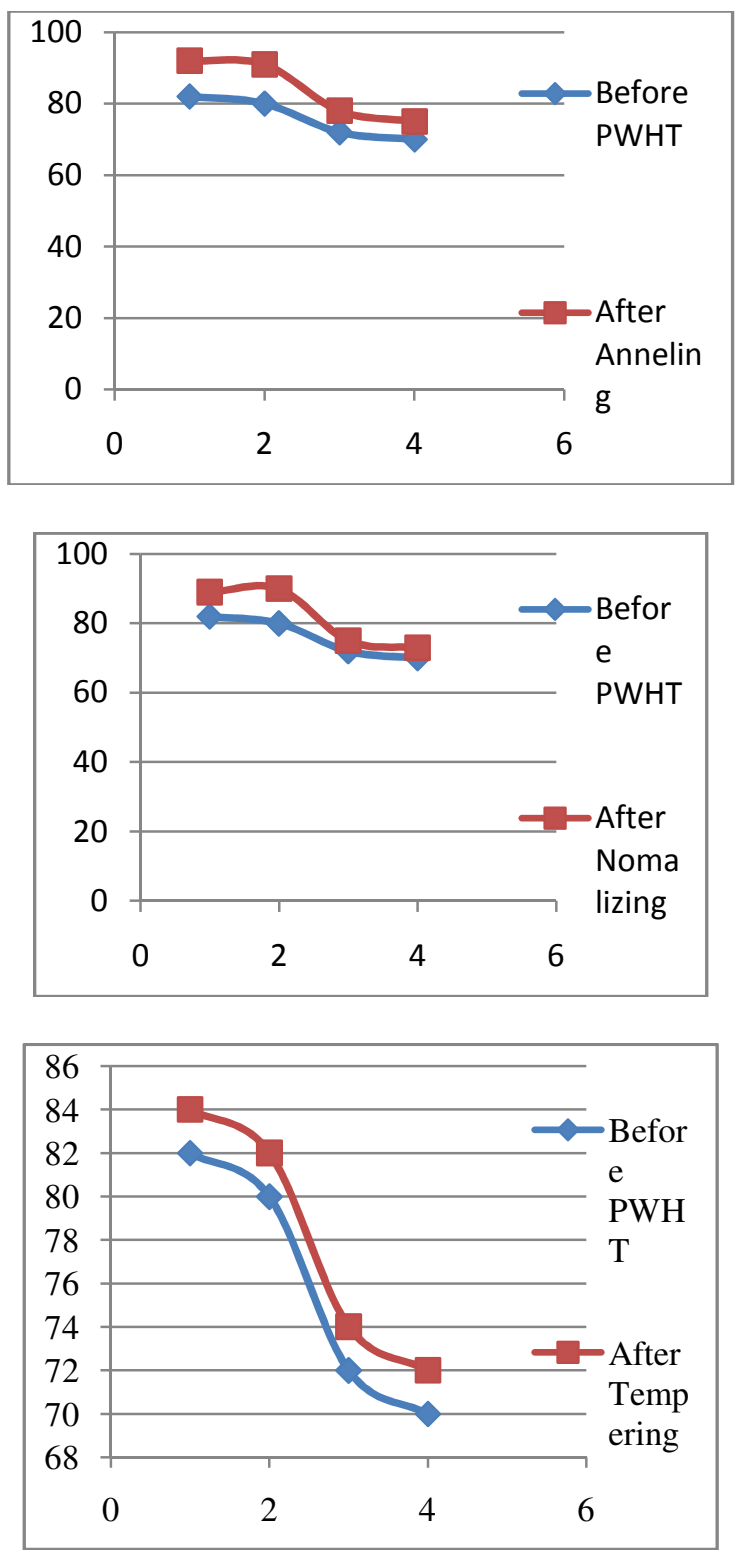

Fig no (3): Impact strength for IS 2062 \& IS $103 \mathrm{Cr} 1$ joint at low heat input \& high heat input for both

\subsection{Hardness:}

B.H.T \& A.H.T of each conditions.

Hardness was found to be a reliable method of estimating the yield and tensile strength of the different zones of the weldment before PWHT and after PWHT. The tensile data obtained from the sections of B.M, W.Z and HAZ could be useful to identify industrial requirements. A practical standpoint, hardness measurements are quicker and more straightforward than numerical calculation of the HAZ. Especially at the welded zone of similar material hardness is $15.85 \%$ is increased for the before heat treatment condition test samples in table no:4 and fig no:4. 
International Journal of Advances in Materials Science and Engineering (IJAMSE) Vol.4, No.3, July 2015

\begin{tabular}{|c|c|c|c|c|c|c|c|c|c|}
\hline & S.No & $\begin{array}{c}\text { Current } \\
\text { (amps) }\end{array}$ & $\begin{array}{l}\text { Voltage } \\
\text { (volts) }\end{array}$ & $\begin{array}{l}\text { Welding } \\
\text { Speed } \\
(\mathrm{mm} / \mathrm{sec})\end{array}$ & $\begin{array}{c}\text { B.M } \\
\text { (IS } \\
2062)\end{array}$ & $\begin{array}{l}\text { H.A.Z } \\
\text { (IS } \\
2062 \text { ) }\end{array}$ & W.Z & $\begin{array}{c}\text { H.A.Z } \\
\text { (IS } \\
103 \\
\text { Cr1) } \\
\end{array}$ & $\begin{array}{c}\text { B.M } \\
\text { (IS } \\
103 \\
\text { Cr1) } \\
\end{array}$ \\
\hline 1. & \multirow{2}{*}{ BHT } & 160 & 25 & 3.43 & 76 & 78 & 103 & 88 & 81 \\
\hline 2. & & 180 & 28 & 3.43 & 57 & 65 & 93 & 79 & 70 \\
\hline 3. & \multirow{2}{*}{ Annealing } & 160 & 25 & 3.43 & 86 & 90 & 108 & 96 & 100 \\
\hline 4. & & 180 & 28 & 3.43 & 73 & 77 & 94 & 88 & 86 \\
\hline 5. & \multirow{2}{*}{ Tempering } & 160 & 25 & 3.43 & 65 & 68 & 88 & 79 & 79 \\
\hline 6. & & 180 & 28 & 3.43 & 60 & 76 & 70 & 67 & 60 \\
\hline 7. & \multirow{2}{*}{ Normalizing } & 160 & 25 & 3.43 & 86 & 90 & 108 & 96 & 100 \\
\hline 8. & & 180 & 28 & 3.43 & 73 & 77 & 94 & 88 & 86 \\
\hline
\end{tabular}

Table no (4): Hardness results for IS 2062 \& IS 103 Cr1 joint for before heat treatment.
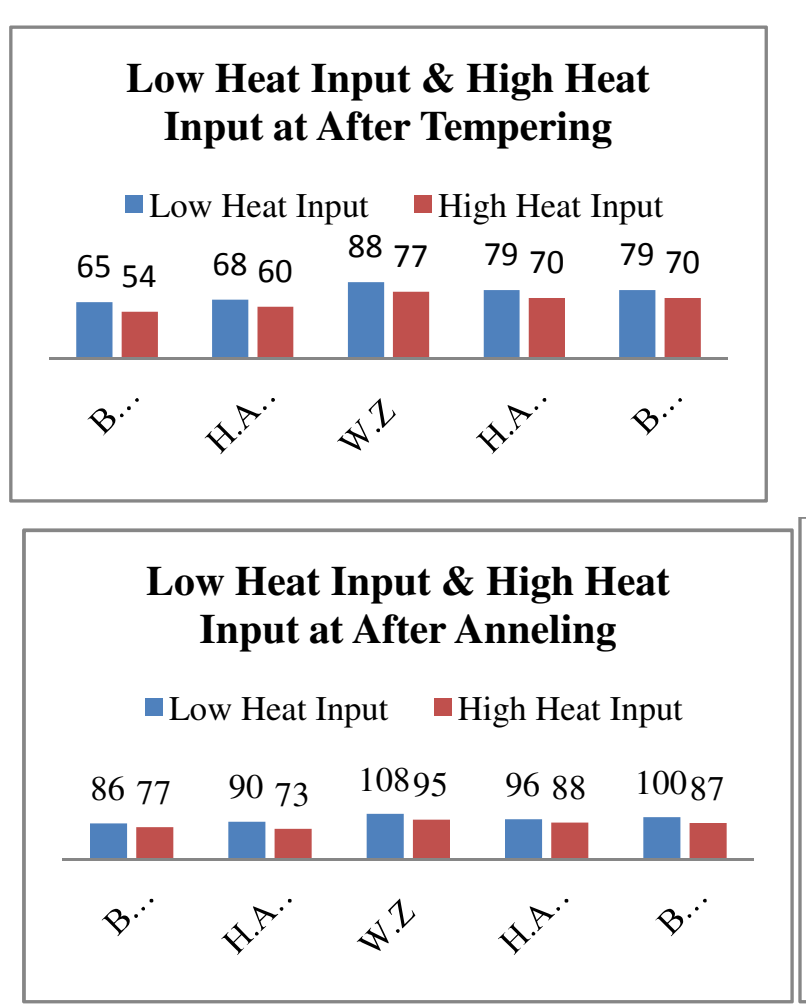
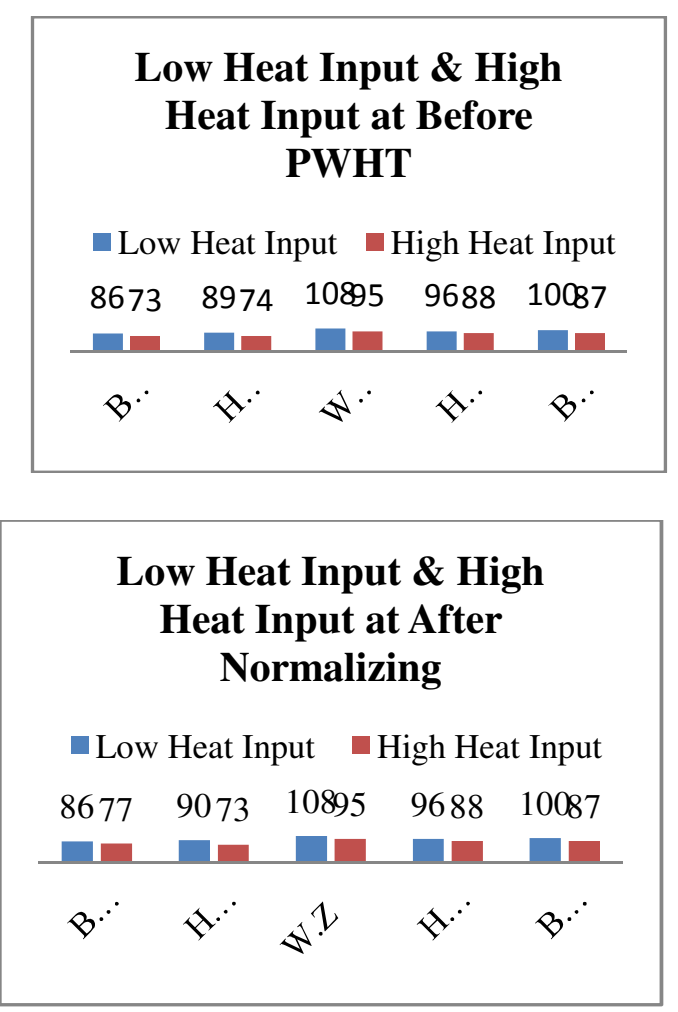

Fig no (4): Hardness for IS 2062 \& IS 103 Cr1 joint at low heat input \& high heat input for both B.H.T \& A.H.T of each conditions. 


\section{Conclusions:}

In this work IS2062 of $10 \mathrm{~mm}$ thick of the plate is used as single V-type grooved weldment,optimal post weld heat treatment processes are used; which are derived from the industrial experience and literature for the following annealing, normalizing and tempering conditions. Tensile test, harpy-V test and hardness samples are evaluated from the IS2062 as compared to the before PWHT conditions. This work is effectively used to improve the properties of weldment by using optimal PWHT processes. Particularly in between HAZ and WZ some cracks are initiated, finally they are propagated during the preparation of samples. These are observed in micro hardness examinations at different zones of weldment.

\section{References:}

[1] Ramazan Kayacan, Remzi Varol, Olcay Kimilli "The effects of pre-and post-weld heat treatment variables on the strain-age cracking in welded Rene 41 components" Materials Research Bulltein 39 (2004) 2171-2186.

[2] Ritter JC, Dixon BF. "Improved properties in welded HY80 steel for Australian warship.Welding journals (1987);66(3):33-44.

[3] Brosilow R. "High strength steels: a progress report in Welding", journal of Design Material fabrication (1991),64(11):40-44.

[4] Sampath K,Civis DA, Kleinosky MJ. "Effects of GMA welding conditions on high strength steel weld metal properties for ship structures.Proceedings of International symposium on low-carbon steels for the warrendale, Minerals and Material science (TMS),(1993)539-548.

[5] MIL-STD-1688 Fabrication,Welding and inspection of HY80/100 steel submerged applications.

[6] ASTM E8M-90a standard test method for tension testing of metallic materials.

[7] ASTM E23 standard test method for notched bar impact testing of metallic materials.

[8] MIL-STD-16216G ship steels late,alloy, structural HY strength.

[9] Cakici B. Investigation of mechanical properties of HY 80 steel joints, welded by using arc welding methods, MSc Thesis.Kocaeli University, Graduate School of Natural and Applied Sciences; May 2002.

[10] Gungor ON. The effects of welding processes on the mechanical properties of the welded joint and HAZ for the quenched and tempered HY 80 high strength low alloy steel. MSc Thesis, Kocaeli University, Graduate School of Natural and Applied Sciences; October 1996.

[11] Allvac Rene 41 Technical deta, Teledyne Allvac Inc., Israel,(1999).

[12] R.F.Decker,E.F.Bradley, "Materials for elevated temperature application Ameriacan society for metals,(1979);275-297.

[13] C.P. Sullivan, M.J. Donachie, Source book on "Material for Elevated Temperature applications" , Ameriacan society for metals,(1997);250-259.

[14] C.R.Brooks, Heat treatment, structure and properties of non ferrous alloys, American society for metals, Ohio,(1984)139-227. 